\title{
Literasi dan Gender: Kesenjangan yang Terjadi di Tingkat Pendidikan Anak Usia Dini
}

\author{
Rizki Amaliah Ritonga $\otimes_{1}$, Panggung Sutapa ${ }^{2}$ \\ Pendidikan Anak Usia Dini, Universitas Negeri Yogyakarta \\ DOI: $\underline{10.31004 / \text { obsesi.v5i1.749 }}$
}

\begin{abstract}
Abstrak
Rendahnya literasi anak laki-laki dibanding anak perempuan sampai saat ini masih menjadi perhatian dalam bidang penelitian. Penelitian ini bertujuan untuk mengeksplorasi kesenjangan gender dalam keterampilan literasi yang ditinjau dari aktifitas bermain selama di sekolah. Metode penelitian dalam artikel ini adalah kajian pustaka dengan mengumpulkan berbagai data-data dari karya tulis ilmiah, kemudian dikaji untuk dihubungkan dengan penelitian untuk pemecahan masalah. Secara umum, hasil penelitian menunjukkan bahwa peran gender mempengaruhi anak dalam pemilihan aktifitas sehari-hari dan pemilihan area bermain di taman kanak-kanak. Anak laki-laki lebih memilih area bermain yang di dalamnya sedikit keterlibatan anak perempuan. Sementara itu aktiftas-aktifitas yang dihindari anak lakilaki di taman kanak-kanak memiliki fasilitas yang dapat mendukung pengalaman literasi.
\end{abstract}

Kata Kunci: gender; literasi; kesenjangan; di bawah prestasi.

\begin{abstract}
The low literacy of boys compared to girls is still a concern in the research field. This study aims to explore the gender gap in literacy skills in terms of play activities while in school. The research method in this article is a literature review by collecting various data from scientific papers, then studying it to be linked with research for problem-solving. In general, the results of the study indicate that gender roles influence children in choosing daily activities and in choosing play areas in kindergarten. Boys prefer play areas where girls have little involvement, while activities that boys avoid in kindergarten have facilities that can support literacy experiences
\end{abstract}

Keywords: Gender; Literacy; Gap; Underachievement.

Copyright (c) 2020 Rizki Amaliah Ritonga, Panggung Sutapa

$\triangle$ Corresponding author :

Email Address : Rizkyamaliahritonga@gmail.com (Medan, Sumatera Utara)

Received 5 September 2020, Accepted 16 September 2020, Published 17 September 2020 


\section{PENDAHULUAN}

Masa prasekolah begitu penting dalam membangun perkembangan anak (Perlman \& Fletcher, 2008) di mana dalam masa ini juga merupakan titik dasar dalam membantu anak untuk membangun perkembangan sikap, keterampilan, pengetahuan, dan daya cipta (Fauziddin, 2017) tidak terkecuali pada perkembangan literasi, sehingga harapannya kelak anak mampu menyesuaikan diri dengan lingkungannya. Sebelum anak usia dini menunjukkan bacaan formal, anak-anak akan terlebih dahulu memperoleh keterampilan prapengetahuan, pengetahuan serta sikap tertentu yang biasa disebut dengan emergent literacy, keterampilan tersebut merupakan dasar untuk perkembangan literasi pada anak (Deasley et al., 2018).

Emergent literacy mencakup beberapa keterampilan literasi inti yakni, pemrosesan fonologis dan keterampilan kosakata yang merupakan hal penting dalam pemerolehan kemampuan untuk membaca, termasuk pemahaman teks, abjad dan kefasihan (Pyle, Poliszczuk, et al., 2018). Pemahaman teks mencakup proses ganda dari penalaran naratif dan pertumbuhan kosakata (National Reading Panel, 2000). Abjad mencakup pengetahuan alfabet serta kesadaran fonemik. Di mana kesadaran fonemik sebagai prediktor awal yang sangat berperan dalam keterampilan membaca anak di kemudian hari (Pyle, Poliszczuk, et al., 2018). Yang terakhir, kefasihan mencakup keterampilan membaca dengan akurasi, ekspresi dan kecepatan (Fuchs et al., 2019). Seluruh komponen inti dari literasi di atas merupakan keterampilan yang sangat penting untuk dimiliki anak yang berpengaruh terhadap akademik nantinya (McClelland et al., 2006).

Mengingat betapa pentingnya keterampilan tersebut, saat ini orang tua dan pendidik sangat serius dalam memperkaya dan menstimulasi kemampuan literasi anak sejak dini (Moriarty, 2002). Beberapa penelitian melaporkan bahwasanya keterampilan membaca yang buruk ketika memasuki sekolah biasanya keterampilan membacanya akan tetap buruk, keterampilan membaca dan menulis ini akan memiliki hubungan jangka panjang yang positif untuk hasil akademik sekolah formal anak pada tahun-tahun selanjutnya serta menjadi penunjang bagi anak untuk dapat berkontribusi di masyarakat kelak (Cunningham \& Stanovich, 1997). Ini menandakan bahwasanya, memberikan peluang dan kesempatan pada anak untuk menstimulasi keterampilan literasi sejak masuk taman kanak-kanak awal sangat penting (Perlman \& Fletcher, 2008).

Mengembangkan keterampilan literasi semakin dianggap penting ketika banyak peneliti yang melaporkan bahwasanya ada kesenjangan gender dalam kemampuan literasi. Seperti yang dilaporkan oleh Thomas bahwasanya lebih sedikitnya anak laki-laki yang mendapat skor tinggi dalam membaca, sedikitnya anak laki-laki yang melakukan aktifitas santai dengan membaca, serta lebih banyaknya anak laki-laki yang memiliki prestasi lebih rendah ketimbang anak perempuan untuk tes membaca standar di kelas SD awal (Thomas, 2019). Dalam dua dekade terakhir kinerja anak laki-laki dalam literasi tertinggal dari anak perempuan (Mohd-Asraf \& Abdullah, 2016); (Skelton \& Francis, 2011); (Watson et al., 2010); (Prioletta \& Pyle, 2017). Sekitar tahun 2006, telah terjadi kesenjangan gender yang cukup besar yaitu dalam bidang membaca, hal ini ditandai dengan tingginya skor rata-rata anak perempuan dibanding anak laki-laki dalam membaca tulisan (Watson et al., 2010). Temuantemuan tersebut sudah dikonfirmasi di seluruh peneliti, tingkat kelas/usia, dan populasi (Below et al., 2010). Hal tersebut merupakan permasalahan yang kemudian menjadi kekhawatiran dan keprihatinan dibanyak Negara (Mohd-Asraf \& Abdullah, 2016). Meningkatnya kekhawatiran dan keprihatinan masyarakat terhadap kinerja literasi anak lakilaki yang rendah, entah bagaimana caranya dapat berubah menjadi kepanikan moral yang akhirnya melenceng terhadap maskulinitas yang beresiko serta berubah menjadi perhatian seputar kinerja maskulinitas laki-laki (Alloway, 2000). Keprihatinan yang berubah arti itu menjadikan anak laki-laki dan anak perempuan adalah pesaing dalam belajar. 
Berdasarkan kajian dari penelitian terdahulu ditemukan fakta bahwa kesenjangan gender dalam literasi diakibatkan oleh sedikitnya peran laki-laki sebagai praktisi pendidikan di taman kanak-kanak (Prioletta \& Pyle, 2017). Penelitian lainnya mengatakan bahwa kesenjangan gender dalam kemampuan literasi terjadi diakibatkan karena adanya "maskulinitas" dan "feminitas" yang telah terkonstruk di dalam fikiran anak yang mengakibatkan pemilihan kegiatan apa yang dapat dilakukan agar tetap terlihat seperti "anak laki-laki sejati" (Skelton \& Francis, 2011). Selanjutnya ada banyak penelitian yang melaporkan bahwa bermain sangat terbukti memberikan manfaat untuk kemajuan kemampuan literasi anak-anak (Pyle, Prioletta, et al., 2018), tetapi mengapa sampai saat ini kemampuan literasi beberapa anak laki-laki masih saja jauh tertinggal dari anak perempuan?. Dengan pertanyaan dan pemaparan latar belakang di atas, maka tujuan artikel ini adalah untuk mengeksplorasi bagaimana peran gender dapat menjadi pembatas kemampuan literasi anak laki-laki melalui pemilihan permainan.

\section{METODOLOGI}

Penelitian ini menggunakan metode kepustakaan. Kajian pustaka atau kepustakaan adalah salah satu bagian yang sangat penting dalam penulisan karya ilmiah karena digunakan untuk menjawab berbagai permasalahan penelitian yang bersumber dari berbagai kumpulan hasil karya ilmiah sebelumnya (Hasanah \& Sugito, 2020). Kegiatan penelitian menggunakan metode kajian pustaka dimulai dengan pengumpulan data-data yang berasal dari berbagai karya tulis ilmiah yang relevan dengan objek penelitian sehingga masalah dapat dipecahkan dengan telaah yang mendalam dari sumber-sumber data yang telah terkumpul sebelumnya (Mukarromah, Hafidah and Nurjanah, 2020), sehingga tidak lagi dibutuhkan riset secara langsung di lapangan.

Ada beberapa alasan peneliti menggunakan metode penelitian kajian pustaka, yaitu: 1) masalah penelitian hanya dapat dijawab melalui penelitian kepustakaan; 2) penelitian kepustakaan diperlukan untuk menelaah atau memahami secara mendalam masalah/gejala baru yang sedang berkembag di lapangan; 3) kajian pustaka bisa dipercaya hasilnya untuk menjawab permasalahan penelitian (Wandi \& Mayar, 2019). Penelitian kajian pustaka dilakukan dengan menganilis data secara ringkas dan menafsirkan teori secara mendalam atau biasa disebut analisis isi (Content Analysis). Langkah-langkah penelitian kajian kepustkaan sebagai berikut (Zed, 2014);

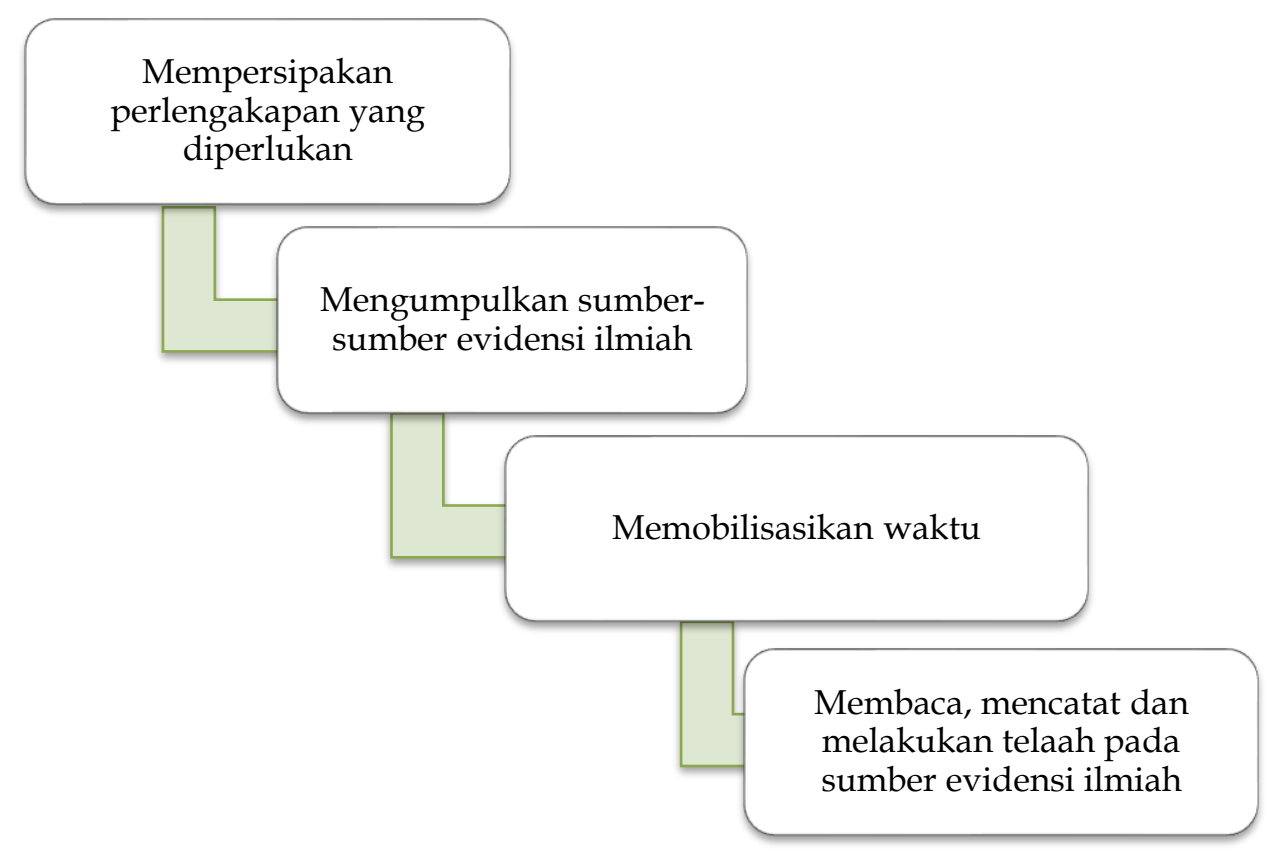

Gambar 1. Langkah-langkah penelitian kajian pustaka 
Penelitian kepustakaan dilakukan dengan cara mengumpulkan data serta informasi terdahulu dari berbagai dokumen, literatur dan karya ilmiah lainnya yang kemudian ditelaah secara mendalam untuk menjadi landasan teori mengenai permasalahan yang diteliti $(\mathrm{N}$. Harahap, 2015). Jadi, sebelum menelaah data secara mendalam peneliti terlebih dahulu harus mempersiapkan peralatan yang diperlukan agar penelitian dapat berjalan ketika sudah memulai kegiatan, kemudian peneliti menyusun dan menentukan sumber utama yang dipergunakan dalam kepentingan penelitian. Selanjutnya, setelah menetukan sumber utama maka peneliti harus mengatur waktu yang dibutuhkan untuk melakukan penelitian. Langkah terakhir dalam penelitian ini adalah peneliti membaca, mencatat dan melakukan telaah pada sumber evidensi ilmiah yang sudah terkumpul hingga akhirnya ditemukanlah informasi yang dibutuhkan oleh peneliti.

\section{HASIL DAN PEMBAHASAN}

Kesenjangan gender dalam kinerja literasi bukanlah hal baru dalam dunia pendidikan. Namun, rendahnya prestasi anak laki-laki dalam kinerja literasi (Melek huruf dan penilaian bahasa) menjadi kekhawatiran yang terus berkembang. Ada beberapa faktor yang berkontribusi dalam kesenjangan gender dalam kinerja literasi; (Prioletta \& Pyle, 2017); (Canadian Council on Learning, 2009); (Mohd-Asraf \& Abdullah, 2016); (Watson et al., 2010).

Tabel 1. Penyebab Kesenjangan

\begin{tabular}{ll}
\multicolumn{1}{c}{$\begin{array}{c}\text { Macam-macam } \\
\text { Kondisi }\end{array}$} & \multicolumn{1}{c}{ Penyebab } \\
\hline $\begin{array}{l}\text { Lingkungan } \\
\text { bermain }\end{array}$ & $\begin{array}{l}\text { Area bermain yang dilabeli “feminim” mengakibatkan anak laki-laki dan } \\
\text { anak perempuan bermain terpisah. padahal area bermain yang telah } \\
\text { dilabeli “feminim” memiliki fasilitas untuk meningkatkan keterampilan } \\
\text { literasi. Contoh, area bermain dramatis dan area bermain seni. Anak laki- } \\
\text { laki cenderung bermain di area balok yang minim fasilitas literasi }\end{array}$ \\
\hline Membaca & $\begin{array}{l}\text { Kegiatan ini lebih sering dilakukan oleh sosok Ibu ketimbang sosok Ayah. } \\
\text { Contoh, membacakan buku cerita sebelum tidur. Menimbulkan persepsi } \\
\text { membaca adalah suatu kegiatan "feminim". }\end{array}$ \\
\hline Sikap dan prilaku & $\begin{array}{l}\text { Anak laki-laki mudah terganggu dalam kegiatan menetap, sementara anak } \\
\text { perempuan mempunyai rentang perhatian yang lebih lama. Sehingga anak } \\
\text { perempuan lebih menurut ketika ada kegiatan literasi (menulis, membaca, } \\
\text { menyusun huruf, dll) }\end{array}$ \\
\hline
\end{tabular}

Berdasarkan kajian hasil penelitian terdahulu yang dirangkum pada tabel di atas, maka ada beberapa penyebab kesenjangan gender dalam kinerja literasi yang akan dijelaskan, yakni:

\section{Lingkungan Bermain}

Lingkungan bermain sangat terbukti memberikan manfaat untuk kemajuan kemampuan literasi anak-anak (Pyle, Prioletta, et al., 2018). Tetapi kenyataannya lingkungan bermain sering terpisahkan oleh peran gender, anak laki-laki dan anak perempuan lebih sering bermain secarah terpisah. Karena ada beberapa area bermain yang dilabeli sebagai "feminim" atau "maskulin" (Prioletta \& Pyle, 2017). Area permainan yang memiliki fasilitas untuk meningkatkan keterampilan literasi adalah area permainan dramatis dan area seni. Bermain dramatis telah diyakini sangat berperan dan menawarkan dukungan untuk kinerja literasi karena mendukung keterampian simbolis (Weisberg et al., 2013), tetapi ternyata kedua area permainan tersebut dianggap sebagai area "feminim" karena anak perempuan yang lebih dominan berada di area permainan tersebut, sehingga tentu saja ini bertentangan dengan maskulinitas anak laki-laki (Prioletta \& Pyle, 2017) dengan demikian area-area yang memasukkan materi untuk kinerja literasi dikaitkan pada kegiatan "feminim". 


\section{Membaca}

Kepercayaan-kepercayaan yang telah terkonstruk dalam fikiran anak akan menjadi penentu dalam melakukan aktifitas. Ketika anak laki-laki mendapat kesulitan atau terkendala dalam membaca, di sini sebenarnya anak akan bertemu dengan konflik yang cukup serius karena adanya tuntutan maskulinitas agar tetap menjaga "wibawa". Hal tersebutlah yang dinamakan dengan negatifnya konstruksi maskulinitas untuk anak, sehingga membuat anak laki-laki enggan untuk mengakui kesulitan serta enggan untuk meminta bantuan atas apa yang saat itu tidak dipahaminya (Skelton \& Francis, 2011).

Selain itu anak laki-laki sering kali menganggap membaca adalah sebagai aktifitas gender (Canadian Council on Learning, 2009). Anak laki-laki membangun persepsi bahwa aktifitas membaca sebagai kegiatan "feminim" sehingga mengurangi motivasi membaca. Selain itu, (Deasley et al., 2018) juga menemukan faktah bahwa ketimbang ayah, ibu adalah sosok yang paling sering berperan dalam membacakan buku untuk anak-anak. Melihat peran membaca yang sering dilakoni oleh wanita, maka menimbulkan persepsi anak laki-laki bahwa kegiatan membaca adalah sebagai suatu kegiatan yang "feminim" dan itu sangat bertentangan dengan kode etik "maskulin".

\section{Sikap dan Prilaku}

Ketika anak memasuki pendidikan anak usia dini, mereka telah menyadari bagaimana peran serta norma gender yang dapat diterima oleh orang lain di sekitar mereka, sebagai contoh sederhana dalam stereotip warna, anak-anak cenderung memilih warna biru untuk laki-laki dan merah muda untuk anak perempuan. Anak-anak belajar mengobservasi peranperan gender melalui menonton dan meniru yang dikatakan ataupun yang dilakukan orang dewasa dan teman sebaya (A. Harahap, 2019) yang juga kegiatan di sekolah secara tidak langsung seringkali memperkuat kepercayaan meraka tentang seks dan gender (Prioletta \& Pyle, 2017).

Sebuah studi oleh (Mohd-Asraf \& Abdullah, 2016) juga menemukan fakta yang sejalan dengan penelitian terdahulu yang dilakukan oleh (Bonomo, 2010) yang mengatakan bahwa ketika di dalam kelas, anak perempuan memiliki rentang perhatian yang lebih tinggi dibanding anak laki-laki, sedangkan anak laki-laki lebih tertarik dengan kegiatan dengan unsur kinestetik sehingga merasa sulit untuk diam dan mengerjakan tugas (Deasley et al., 2018) anak perempuan juga mudah mengikuti perintah yang diinstruksikan. Ketika diinstrusikan untuk membaca, maka mereka akan duduk dan membaca. Temuan tersebut berkaitan dengan perbedaan berbasis gender di dalam pembelajaran, yaitu perempuan mempunyai kemampuan dalam mengahadapi transisi pelajaran yang begitu baik (MohdAsraf \& Abdullah, 2016).

Sangat jelas bahwa hasil temuan di atas merupakan penegasan identitias anak laki-laki yang membuat dirinya sebagai lawan "feminitas" (Watson et al., 2010). Pelabelan tentang "menjadi laki-laki" dan pemikiran seputar apa yang dikategirokan sebagai perilaku maskulin mengakibatkan keengganan yang kuat untuk anak laki-laki berpartisipasi dalam kegiatan atau permainan yang dapat membangun literasi. Namun, (Below et al., 2010) menyatakan bahwa kesenjangan gender dalam keterampilan literasi dipengaruhi oleh penyebab budaya/sosial atau lingkungan, dan biasanya asumsi dan perilaku guru terhadap anak muridnya akan mempengaruhi praktik apa yang akan diberikannya kepada muridnya. Penting untuk diingat bahwa bahkan dari kecil anak sudah menjadi agen aktif yang membangun pengalaman mereka dengan berbagai cara (Carroll et al., 2019). Sehingga peran guru dan asumsi yang telah terpatri di pemikirannya diharapkan dapat memberikan kontribusi yang sama untuk anak laki-laki dan anak perempuan, tanpa membedakan perlakuan. Sangat penting bagi guru untuk mengenali konflik dalam diri anak laki-laki sebagaimana tuntutan untuk menjadi "lelaki sejati" sesuai maskulinitas yang dibarengi dengan tuntutan literasi (Alloway, 2000). Perlakuan yang diberikan guru diharapkan mampu meningkatkan minat literasi pada anak, karena minat baca tulis adalah prediktor terpenting 
dan terkuat dari keterampilan literasi (Carroll et al., 2019). Selain itu keterampian literasi yang tinggi memberikan peran yang cukup besar dalam memperluas pengetahuan, memiliki pemikiran terbuka dan kritis (Chall \& Jacobs, 2003).

Berbagai argumen dan teori tengah berusaha dan berbagi keyakinan menjelajahi kesenjangan gender dalam literasi. Peneliti mencoba menghubungkan kesenjangan ini dengan faktor biologis, ada keyakinan tentang anak laki-laki dan anak perempuan berbeda karena perbedaan bilogis menyebabkan perbedaan tingkah laku dan juga bahwa otak diantara dua jenis kelamin ini terorganisir dan terstruktur secara berbeda (Watson et al., 2010); (Prioletta \& Pyle, 2017). Argumen-argumen tersebut menciptakan pandangan bahwasanya kedua jenis kelamin ini telah memiliki karakteristik yang tetap atau melekat sehingga menentukan perilaku dan minat alami mereka, itu berarti gender bersifat alami dan tetap. Beda dengan pendapat yang dikemukakan (Skelton \& Francis, 2011) bahwasanya literasi dan gender terbangun secara sosial, yang mana literasi dianggap sebagai kegiatan "feminim" pada akhirnya karena adanya konstruksi literasi sebagai feminim mengakibatkan keterlibatan anak laki-laki dalam kegiatan literasi ini terhambat. Namun, berbeda dengan pendapat yang diungkapkan oleh (Wayne John, 2008) bahwa yang berkontribusi pada krisis identitas bagi anak laki-laki adalah sekolah yang menganut "feminim", sehingga dibutuhkan perekrutan guru laki-laki untuk membantu anak laki-laki bersaing dengan anak perempuan. Bagaimanapun, menghapus kesenjangan gender untuk kemampuan literasi tidaklah mudah, tetapi tidak ada salahnya untuk mencoba menantang pemahaman maskulinitas agar berkurangnya masalah pencapaian keterampilan literasi anak.

\section{Strategi Pedagogis}

Keterampilan keaksaraan berkembang selama tahun-tahun awal prasekolah yang dipengaruhi dari sifat serta tingkat praktik keaksaraan di rumah (Saçkes, Işıtan, Avci, \& Justice, 2016). Kemudian, ketika mulai memasuki taman kanak-kanak mereka sudah mulai memiliki keterampilan baca tulis (Pyle, Prioletta, et al., 2018). Namun, tidak sedikit anak lakilaki yang menganggap bahwa kegiatan-kegiatan yang dapat menunjang kemampuan literasi seperti membaca atau bermain di area-area tertentu merupakan kegiatan yang menunjukkan sifat feminim, dan ini tentu menjadi unsur utama yang mengurangi minat mereka dalam kegiatan membaca (Canadian Council on Learning, 2009). Untuk itu diperlukan strategi yang dapat menyempitkan kesenjangan tersebut. Mengingat kembali teori (Froebel, 2010) yang memperkenalkan taman kanak-kanak sebagai konteks menyenangkan anak-anak untuk berkembang dan tumbuh, dan romantisme masa kanak-kanak dapat dipupuk.

Peran guru adalah menyediakan lingkungan bermain yang kaya akan literasi (Ihmeideh, 2015). Walaupun, diketahui bahwa tidak mudah untuk mengintegrasikan bermian dan akademik di sekolah. Guru bisa menjadi fasilitator yang menciptakan kondisi bermain, bahkan bisa terlibat dalam menghubungkan serta mendiiskusikan cerita ataupun narasi pribadi yang menjadi sumber daya kaya sebagai umpan balik penanaman literasi anak (de Haan, 2005). Fokus dari pendekatan ini adalah eksploitasi, eksplorasi, serta penanaman literasi.

Kehadiran guru juga sekiranya dapat membantu anak laki-laki untuk mulai mempersempit pemikiran "maskulin", misalnya memberikan penguatan dan membangun kepercayaan anak laki-laki bahwa tidak masalah untuk menggunakan area seni dan area dramatis untuk bermain bersama anak perempuan. Dengan adanya penguatan dari guru, membuka kemungkinan untuk anak-anak bermain bersama dalam semua area dan bebas bereksplorasi dalam permainan mereka (Prioletta \& Pyle, 2017). 


\section{Tabel 2. Kerangka Alternatif}

\begin{tabular}{ll}
\hline \multicolumn{1}{c}{ Macam-macam } & \multicolumn{1}{c}{ Cara } \\
\hline Bermain & $\begin{array}{l}\text { Menyediakan permainan yang kaya akan literasi. Menjadi fasilitator dan } \\
\text { motivator yang terlibat daam menghubungkan serta mendiskusikan cerita } \\
\text { yang menjadi sumber daya kaya sebagai umpan balik penanaman literasi }\end{array}$ \\
\hline $\begin{array}{l}\text { Mengikis permainan } \\
\text { "maskulim/feminim" }\end{array}$ & $\begin{array}{l}\text { Kehadiran guru sekiranya dapat membantu anak laki-laki untuk mulai } \\
\text { mempersempit pemikiran "maskulin/feminim", misalnya memberikan } \\
\text { penguatan dan membangun kepercayaan anak laki-laki bahwa tidak } \\
\text { masalah untuk menggunakan area seni dan area dramatis untuk bermain } \\
\text { bersama anak perempuan }\end{array}$ \\
\hline $\begin{array}{l}\text { Penggunaan media } \\
\text { populer }\end{array}$ & $\begin{array}{l}\text { Media populer (smartphone dan laptop) dapat menghasilkan pengetahuan } \\
\text { yang besar bagi anak jika digunakan sebagai alat untuk menambah }\end{array}$ \\
& $\begin{array}{l}\text { pengetahuan guna meningkatkan literasi, tentunya dengan pengawasan dan } \\
\text { instruksi dari orang tua maupun guru. }\end{array}$ \\
\hline
\end{tabular}

Pemahaman laki-laki terhadap membaca sebagai kegiatan "feminim" membuat intensitas waktu membaca mereka tidak sesering anak perempuan (Canadian Council on Learning, 2009). Mengatasinya adalah dengan membangun antusiasme anak terhadap buku sejak usia dini. Dimulai dengan mengenalkan buku-buku cerita seputar hewan, olah raga, atau kisah petualang. Yang terpenting adalah untuk mengikis pemikiran anak bahwasanya membaca bukan hanya kegiatan "feminim" ini adalah strategi yang bisa digunakan untuk memotivasi anak laki-laki sejak usia dini untuk membaca dan membangun sikap positif terhadap membaca.

Penelitian lain melaporkan bahwa media populer lainnya juga dapat menjadi alat yang bermanfaat bagi penunjang perkembangan literasi awal anak. selurah anak pada masa ini sangat tertarik dengan media populer, tentu meminkan peran yang penting dalam kegiatan sehari-hari mereka dalam permainan (Ashton, 2005). Namun, kurangnya pengetahuan dan harapan literasi keluarga dan guru tentang dampak teknologi terhadap literasi anak mengakibatkan mereka tetap berfikir bahwa media tidak memiliki pengaruh yang baik untuk literasi anak. Padahal, media populer dapat menghasilkan pengetahuan yang besar bagi anak jika digunakan sebagai alat untuk menambah pengetahuan guna meningkatkan literasi anak (Beavis, 2000) tentunya dengan pengawasan dan instruksi yang benar dari orangtua maupun guru.

Akhirnya, seperti pertanyaan yang diungkapkan oleh (Watson et al., 2010) yaitu, bukankah lebih baik untuk menantang kepercayaan maskulinitas yang terbangun secara sosial dengan pendidikan/pengajaran daripada menciptakan strategi serta memperbanyak perekrutan sumber daya yang ramah anak laki-laki?. Pertanyaan tersebut memberikan makna yang cukup berarti bahwasanya pemahaman anak laki-laki "menjadi pria sejati" yang menyebabkan anak enggan mengikuti kegiatan yang berhubungan dengan literasi harus dikikis dan ditantang. Ini berarti pengetahuan serta pemahaman para guru harus lebih ditingkatkan, yaitu dengan diberikannya pelatihan profesional agar mampu menciptakan lingkungan ramah anak yang mempersempit "kesenjangan gender" yang terjadi di kelas (Skelton \& Francis, 2011).

\section{SIMPULAN}

Kesenjangan gender dalam kinerja literasi dipengaruhi oleh berbagai kondisi, yaitu; lingkungan bermain yang terpisahkan oleh gender, membaca sebagai aktifitas gender, dan sikap dan prilaku. Kondisi-kondisi tersebut menawarkan dukungan yang berbeda terhadap kinerja literasi anak. Mempersempit dan mengikis kesenjangan tersebut bukanlah suatu tugas yang mudah tetapi guru dan orang tua tetap harus mempertimbangkan strategi yang dapat diterapkan untuk anak, karena strategi yang terbaik akan memberikan dampak yang baik pula untuk kinerja literasi anak kedepannya. 


\section{UCAPAN TERIMA KASIH}

Terimakasih untuk Program Pascasarjana dan kampus Universitas Negeri Yogyakarta serta kepada dosen pembimbing yaitu Panggung Sutapa yang telah membimbing serta mendukung penyelesaian artikel ini. Yang terspesial ucapan terimakasih untuk kedua orang tua dan keluarga yang menjadi sumber motivasi disegala situasi.

\section{DAFTAR PUSTAKA}

Alloway, N. (2000). Exploring Boys' Literacy Performance at School: Incorporating and Transcending Gender. Contemporary Issues in Early Childhood, 1(3), 333-337. https://doi.org/10.2304/ciec.2000.1.3.9

Ashton, J. (2005). Barbie, the wiggles and harry potter. can popular culture really support young children's literacy development? International Journal of Phytoremediation, 21(1), 31-40. https:// doi.org/10.1080/13502930585209541

Beavis, C. (2000). Popular culture, textual practice and identity: literacy and the new technologies in the middle years of schooling, AARE 2000 Conference Papers, pp. In Paper presented at the Australian Association for Research in Education (AARE) Conference held at the University of NSW.

Below, J. L., Skinner, C. H., Fearrington, J. Y., \& Sorrell, C. A. (2010). Gender differences in early literacy: Analysis of kindergarten through fifth-grade Dynamic Indicators of Basic Early Literacy Skills probes. In School Psychology Review (Vol. 39, Issue 2, pp. 240-257).

Bonomo, V. (2010). Gender Matters in Elementary Education Research-based Strategies to Meet the Distinctive Learning Needs of Boys and Girls Distinctive Learning Needs of Boys and Girls in Elementary Education Those findings do not necessarily mean that boys learn one. Educational Horizons, 88(4), 257-264.

Canadian Council on Learning. (2009). Why boys don't like to read: gender differences in reading achievement. Lessons in Learning.

Carroll, J. M., Holliman, A. J., Weir, F., \& Baroody, A. E. (2019). Literacy interest, home literacy environment and emergent literacy skills in preschoolers. Journal of Research in Reading, 42(1), 150-161. https://doi.org/10.1111/1467-9817.12255

Chall, J., \& Jacobs, V. (2003). The Classic Study on Poor Children's Fourth-Grade Slump | American Federation of Teachers. American Educator.

Cunningham, A. E., \& Stanovich, K. E. (1997). Early reading acquisition and its relation to reading experience and ability 10 years later. Developmental Psychology, 33(6), 934-945. https:// doi.org/10.1037/0012-1649.33.6.934

de Haan, D. (2005). Social pretend play: Potentials and limitations for literacy development. International Journal of Phytoremediation, 21(1), 41-55. https:// doi.org/10.1080/13502930585209551

Deasley, S., Evans, M. A., Nowak, S., \& Willoughby, D. (2018). Sex Differences in Emergent Literacy and Reading Behaviour in Junior Kindergarten. Canadian Journal of School Psychology, 33(1), 26-43. https:// doi.org/10.1177/0829573516645773

Fauziddin, M. (2017). Upaya Peningkatan Kemampuan Bahasa Anak Usia 4-5 Tahun melalui Kegiatan Menceritakan Kembali Isi Cerita di Kelompok Bermain Aisyiyah Gobah Kecamatan Tambang. Jurnal Obsesi: Jurnal Pendidikan Anak Usia Dini, 1(1), 42-51. https:// doi.org/10.31004/obsesi.v1i1.30

Friedrich Froebel. (2010). Pedagogies of the kindergarten. In I. M. Lilley (Ed.), Friedrich Froebel: A selection from his writing. NY: Cambridge at the University Press.

Fuchs, L. S., Fuchs, D., Hosp, M. K., \& Jenkins, J. R. (2019). Oral Reading Fluency as an Indicator of Reading Competence: A Theoretical, Empirical, and Historical Analysis. In The Role of Fluency in Reading Competence, Assessment, and instruction (pp. 239-256). https:// doi.org/10.4324/9781410608246-3

Harahap, A. (2019). Gender Typing (Pada Anak Usia Sekolah Dasar). Al-Muaddib : Jurnal IlmuIlmu Sosial \& Keislaman, 4(1), 1. https://doi.org/10.31604/muaddib.v1i1.781

Harahap, N. (2015). Penelitian Kepustakaan. Jurnal Iqra', 08(01), 68-73.

Hasanah, N., \& Sugito, S. (2020). Analisis Pola Asuh Orang Tua terhadap Keterlambatan Bicara 
pada Anak Usia Dini. Jurnal Obsesi : Jurnal Pendidikan Anak Usia Dini, 4(2), 913. https://doi.org/10.31004/obsesi.v4i2.456

Ihmeideh, F. (2015). The impact of dramatic play centre on promoting the development of children's early writing skills. European Early Childhood Education Research Journal, 23(2), 250-263. https://doi.org/10.1080/1350293X.2014.970848

McClelland, M. M., Acock, A. C., \& Morrison, F. J. (2006). The impact of kindergarten learningrelated skills on academic trajectories at the end of elementary school. Early Childhood Research Quarterly, 21(4), 471-490. https://doi.org/10.1016/j.ecresq.2006.09.003

Mohd-Asraf, R., \& Abdullah, H. (2016). Elementary Schoolers' Attitudes toward Reading in English: How Boys Feel Relative to Girls. English Language Teaching, 9(6), 134. https:// doi.org/10.5539/elt.v9n6p134

Moriarty, V. (2002). Eager to Learn: educating our preschoolers. National Research Council, National Academy Press, Washington, DC, 2001. ISBN 0-309-06836-3. Infant and Child Development, 11(3), 283-284. https:// doi.org/10.1002/icd.271

Mukarromah, T. T., Hafidah, R., \& Nurjana, N. E. (2020). Kultur Pengasuhan Keluarga terhadap Perkembangan Moral Anak Usia Dini. Jurnal Obsesi : Jurnal Pendidikan Anak Usia Dini, 5(1). https://doi.org/10.31004/obsesi.v5i1.550

National Reading Panel. (2000). Report of the National Reading Panel: Teaching children to read - an evidence-based assessment of the scientific research literature on reading and its implications for reading instruction. In National Institute of Child Health and Human Development. https://doi.org/10.1002/ppul.1950070418

Perlman, M., \& Fletcher, B. A. (2008). Literacy instruction in canadian child care centers. In Journal of Research in Childhood Education (Vol. 23, Issue 2, pp. 139-155). https:// doi.org/10.1080/02568540809594651

Prioletta, J., \& Pyle, A. (2017). Play and gender in Ontario kindergarten classrooms: implications for literacy learning. In International Journal of Early Years Education (Vol. 25, Issue 4, pp. 393-408). https://doi.org/10.1080/09669760.2017.1390446

Pyle, A., Poliszczuk, D., \& Danniels, E. (2018). The Challenges of Promoting Literacy Integration Within a Play-Based Learning Kindergarten Program: Teacher Perspectives and Implementation. Journal of Research in Childhood Education, 32(2), 219-233. https://doi.org/10.1080/02568543.2017.1416006

Pyle, A., Prioletta, J., \& Poliszczuk, D. (2018). The Play-Literacy Interface in Full-day Kindergarten Classrooms. Early Childhood Education Journal, 46(1), 117-127. https://doi.org/10.1007/s10643-017-0852-z

Saçkes, M., Işıtan, S., Avci, K., \& Justice, L. M. (2016). Parents' perceptions of children's literacy motivation and their home-literacy practices: what's the connection? European Early Childhood Education Research Journal, 24(6), 857-872. https:// doi.org/10.1080/1350293X.2014.996422

Skelton, C., \& Francis, B. (2011). Successful boys and literacy: Are "literate boys" challenging or repackaging hegemonic masculinity? Curriculum Inquiry, 41(4), 456-479. https://doi.org/10.1111/j.1467-873X.2011.00559.x

Thomas, K. L. (2019). Building Literacy Environments to Motivate African American Boys to Read. Reading Teacher, 72(6), 761-765. https://doi.org/10.1002/trtr.1784

Wandi, Z. N., \& Mayar, F. (2019). Analisis Kemampuan Motorik Halus dan Kreativitas pada Anak Usia Dini melalui Kegiatan Kolase. Jurnal Obsesi : Jurnal Pendidikan Anak Usia Dini, 4(1), 363. https:// doi.org/10.31004/obsesi.v4i1.347

Watson, A., Kehler, M., \& Martino, W. (2010). The Problem of Boys' Literacy Underachievement: Raising Some Questions. Journal of Adolescent $\mathcal{E}$ Adult Literacy, 53(5), 356-361. https://doi.org/10.1598/jaal.53.5.1

Wayne John, M. (2008). Male Teachers as Role Models: Addressing Issues of Masculinity, Pedagogy and the Re-Masculinization of Schooling. Curriculum Inquiry.

Weisberg, D. S., Zosh, J. M., Hirsh-Pasek, K., \& Golinkoff, R. M. (2013). Talking it up: Play, language development, and the role of adult support. American Journal of Play, 6(1), 39-54.

Zed, M. (2014). Metode penelitian kepustakaan (3rd ed.). yayasan pustaka obor inonesia. 